



\section{Inoculated fermented corn as dietary performance and health enhancer in pigs: literature and in vitro study}

S.J. Koopmans, P. Bikker, P.G. van Wikselaar, and M.M. van Krimpen.

This research was conducted by Wageningen UR Livestock Research, commissioned and funded by the Dutch Ministry of Economic Affairs within the framework of the public-private partnership 'Kleinschalige Bioraffinage' (PPS AF-12040) with project number BO-21.04-001-001.

Wageningen UR Livestock Research

Wageningen, May 2016 
S.J. Koopmans, P. Bikker and M.M. van Krimpen, 2016. Inoculated fermented corn as dietary performance and health enhancer in pigs: literature and in vitro study. Wageningen, Wageningen UR (University \& Research centre) Livestock Research, Livestock Research Report 955.

The multi-microbe probiotics approach may result in the best chance to improve pig performance and health by feeding pigs a diet partly consisting of inoculated fermented corn. A corn specific Lactobacillus amylophilus may be used in combination with one or more pig specific probiotics like Lactobacillus acidophilus, Lactobacillus salivarius, Lactobacillus reuteri, Lactobacillus plantarum and Lactobacillus johnsonii depending on the availability of these strains. Commercially available pig probiotics may be used as alternative source of inoculation, if no restrictions to the use apply. An inoculation level of $0.2-0.3 \%$ to the fermentable substrate seems optimal. The applied fermentation process resulted in a significant increase in the lactic acid content of the fermented corn, without seriously increasing the acetic acid. The in vitro digestibility of fermented corn increased by $6 \%$ as compared to soaked unfermented corn. According to the current review, dietary lactic acid content should amount 4.5 to $36 \mathrm{~g} / \mathrm{kg} \mathrm{DM}$ to have a stimulating effect on gut health and pig performance. To realize such contents in a complete pig diet, the inclusion level of the current fermented corn have to vary between 3.6 to $29 \%$ of DM.

(C) 2016 Wageningen UR Livestock Research, P.O. Box 338, 6700 AH Wageningen, The Netherlands, T +31 (0)317 4839 53, E info.livestockresearch@wur.nl, www.wageningenUR.nl/en/livestockresearch. Livestock Research is part of Wageningen UR (University \& Research centre).

All rights reserved. No part of this publication may be reproduced and/or made public, whether by print, photocopy, microfilm or any other means, without the prior permission of the publisher or author.

The ISO 9001 certification by DNV underscores our quality level. All our research commissions are in line with the Terms and Conditions of the Animal Sciences Group. These are filed with the District Court of Zwolle.

\section{Livestock Research Report}




\section{Table of contents}

Table of contents

Preface

$\begin{array}{lr}\text { Summary } & 7\end{array}$

1

$\begin{array}{ll}\text { Introduction } & 9\end{array}$

$\begin{array}{llr}1.1 & \text { Objectives } & 10\end{array}$

1.2 Sponsor $\quad 10$

2

$\begin{array}{ll}\text { Literature review } & 11\end{array}$

2.1 Review 11

2.2 Conclusions from literature $\quad 12$

3

Effect of corn fermentation on lactic acid concentration and in vitro dry matter digestibility

3.1 Lactic acid in pig diets $\quad 13$

3.2 Material and methods: 13

$\begin{array}{lll}3.3 & \text { Results and discussion } & 14\end{array}$

$\begin{array}{lll}3.4 & \text { Conclusions } & 15\end{array}$ 


\section{Preface}

A literature study was conducted to screen the scientific literature on the effects of natural and inoculated fermentation of pig feed on growth performance and health enhancement in pigs. The ultimate aim of this literature study was to get insight in the mechanisms related to the improved pig production as induced by the probiotic effects of lactobacilli and the growth promoting effects of organic acids as produced during the process of fermentation of chopped corn. Based on the results of the review, corn was fermented, thereby inoculating the mixture with a starch degrading enzyme and lactic acid producing bacteria. The fermented corn was tested in a vitro digestibility study, where after it could be concluded that the in vitro digestibility was improved as compared with the unfermented corn. This research was funded by the Dutch Ministry of Economic Affairs (Top sector Agri \& Food, public-private partnership 'Kleinschalige Bioraffinage').

Marinus van Krimpen

Project leader 


\section{Summary}

The present literature study summarizes the knowledge on fermentation of pig feed by various strains of Lactobacillus, on the generation of dietary organic acids by the fermentation process and, if known, the effects on pig performance and health.

Fermentation of starchy products by strains of Lactobacillus leads to the generation of organic acids, and the combined probiotic effects of strains of Lactobacillus and the effects of organic acids are known for their ability to enhance performance and health of growing pigs. However, the beneficial effects of fermentation on pig economy and well-being depend on the type of microbiota used and of the composition of organic acids generated by fermentation. The process of fermentation can be initiated under natural environmental microbial conditions or can be standardised by inoculation with (blends of) specific bacterial strains. The latter may lead to a more predictable generation of different types of organic acids and the chosen bacterial strains for inoculation of the dietary substrate may act as probiotics, being species-specific, i.e specifically originating from the intestine of pigs.

The main product of fermentation is lactic acid and to a lesser extent acetic acid and some ethanol. The ratio between lactic acid and acetic acid should ideally be $>5: 1$ in pigs diet for performance enhancing effects.

The multi-microbe probiotics approach of Choi et al. may result in the best chance to improve pig performance and health by feeding pigs a diet partly consisting of inoculated fermented chopped corn. A corn specific Lactobacillus amylophilus GV6 may be used in combination with one or more pig specific probiotics like Lactobacillus acidophilus, Lactobacillus salivarius, Lactobacillus reuteri, Lactobacillus plantarum and Lactobacillus johnsonii depending on the availability of these strains. Commercially available pig probiotics may be used as alternative source of inoculation, if no restrictions to the use apply. An inoculation level of $0.2-0.3 \%$ to the fermentable substrate seems optimal.

Based on this review, the effect of corn fermentation treated with a starch degrading enzyme and a probiotic strain on lactic acid concentration was determined. Subsequently, the in vitro dry matter digestibility of unfermented versus fermented corn was determined. It was concluded that the applied fermentation process resulted in a significant increase in the lactic acid content of the fermented corn, without seriously increasing the acetic acid. The in vitro digestibility of fermented corn increased by $6 \%$ as compared to soaked unfermented corn. According to the current review, dietary lactic acid content should amount 4.5 to $36 \mathrm{~g} / \mathrm{kg}$ DM to have a stimulating effect on gut health and pig performance. To realize such contents in a complete pig diet, the inclusion level of the current fermented corn have to vary between 3.6 to $29 \%$ of DM. 


\section{Introduction}

Mechanisms related to the improved pig production as induced by fermentation of pig feed seem to be related to at least two modes of action: effects of probiotics and effects of organic acids.

\section{Probiotics}

Probiotics may be effective in preventing intestinal health problems in pigs (such as diarrhea). Probiotics are living microorganisms beneficial to the health of verterbrates and by introducing probiotics in the intestines, beneficial effects on piglets health can be noticed (Burel, 2012). However, the exact mechanism of action of probiotics is not understood (Heo et al., 2012). Probiotics as an alternative for antibiotics have been studied and reviewed extensively (Barton and Hart, 2001; Verstegen and Williams, 2002; Chander et al., 2007; De Lange et al., 2010; Cho et al., 2011; Burel, 2012; Heo et al., 2012; Allen et al., 2013). Examples of probiotics frequently used in pig farming are Lactobacillus spp., Streptococcus spp., Bifidobacterium spp., Bacillus spp., and yeast (Allen et al., 2013).

Probiotics may have at least five beneficial functions (De Lange et al , 2010) in the gastrointestinal tract of young piglets. The effects of probiotics, however, depend on the bacterial strain used. These five functions are: 1) Stimulate the development of a healthy microbiota-predominated by beneficial bacteria, 2) prevent colonization of enteric pathogenic bacteria in the gut, 3) increase the digestive capacity of the gut and lower it's pH, 4) enhance mucosal immunity, and 5) enhance gut tissue maturation and integrity. However, in order to be a good alternative for in-feed antibiotics, probiotics need to be non-pathogenic, be free of antibiotic resistance genes or have reduced gene transfer functions, survive in feed in the manufacturing process and have a stable activity, be resistant against stomach acids and bile, be able to colonize the gastrointestinal tract, be hostile for pathogens, have high growth rates and low nutrient requirements, be able to produce nutrients, and suppress enteric pathogenic bacterial cells or their metabolites (De Lange et al., 2010; Allen et al., 2013). The overall effectiveness of probiotics as alternative for antimicrobials remains unclear due to the many, difficult to compare experimental studies. The outcome of these studies are inconsistent, due to the many probiotics studied and the lack of standardisation of experimental conditions like the health status of animals (Allen et al., 2013).

\section{Organic acids}

Several researchers have reviewed or studied organic acids as alternatives for antibiotics (Verstegen and Williams, 2002; Apajalahti et al., 2009; De Lange et al., 2010; Burel, 2012; Heo et al., 2012; Papatsiros et al., 2012; Allen et al., 2013; Chu et al., 2013).

Organic acids are known for their antimicrobial activity (Burel, 2012; Papatsiros et al., 2012). The organic acids which have antimicrobial activity are the short-chain acids, widely present in animals and plants. In the large intestines of monogastric animals these acids can be formed through fermentation of carbohydrates. These organic acids may be present in the form of salts with sodium, potassium, or calcium (Partanen and Mroz, 1999; Papatsiros et al., 2012). In-feed organic acids may be present naturally in the feed or be added (Allen et al., 2013).

The most common used organic acids in pig- and poultry diets are: formic, acetic, propionic, butyric, lactic, sorbic, fumaric, malic, tartaric, citric, and benzoic acids (Edmonds et al., 1985; Giesting and Easter, 1985; Partanen and Mroz, 1999; Dibner and Buttin, 2002) and complex blends created by fermentation (Allen et al., 2013). A summation of the organic acids and their positive effects in several studies is given by Papatsiros et al. (2012). The transport route of organic acids in the animal's gastrointestinal tract is given by Mroz et al. (2006).

Organic acids exert their positive effects by influencing the gastrointestinal microbiota by changing the physical conditions of the microbiota and by directly killing some pathogens. (Verstegen and Williams, 2002). The organic acids may give their beneficial effects by the following mechanisms/characteristics: influence buffering capacity of diets, stimulate digestive enzyme activity (for example pepsin) and production/improve pancreatic secretion in the small intestines, balance the microbial population by 
decreasing the growth and survival of pathogenic bacteria and increasing the growth of beneficial bacteria, decrease stomach $\mathrm{pH}$ which in turn improves protein digestion, may lower stomach emptying rate, provide nutrients which are preferred by intestinal tissue and in turn improving mucosal integrity and function, increase nutrient digestibility and limit feed spoilage, directly kill bacteria by antimicrobial activity (Partanen and Mroz, 1999; Partanen, 2001; Knarreborg et al., 2002; Verstegen and Williams, 2002; Diebold and Eidelsburger, 2006; De Lange et al., 2010; Wales et al., 2010; Burel, 2012; Heo et al., 2012). Organic acids can directly kill bacteria by their ability to enter a bacterium, depolarize its membrane, and alter its nutrient transport and synthesis. It is stated that the effects of organic acids are greatest in diets with low essential amino acids and minerals (Verstegen and Williams, 2002). Furthermore, it is stated that organic acids cause little hydrogen-chloride production in the stomach in piglets (Burel, 2012). Contradictory statements are made about the effect of organic acids on the buffering capacity of diets, as Partanen (2001) also already mentioned. Organic acids would reduce buffering capacity of diets (Partanen and Mroz, 1999; Knarreborg et al., 2002; Diebold and Eidelsburger, 2006; Mroz et al., 2006) or organic acids would cause a high buffering capacity of the feed (Burel, 2012). Both would however result in the positive effects of organic acids.

Whether organic acids are a good alternative for antibiotics depends on their microbial mode of action (Verstegen and Williams, 2002). The positive effects of organic acids seem to be dependent on the combination of organic acids used, the animal itself, and the feed (Partanen, 2001; Decuypere and Dierick, 2003; Mroz et al., 2006). Perhaps the smell of the feed after addition of organic acids can influence the palatability of the feed, since some organic acids have a strong odour. For an overview of the different odours from some short chain fatty acids including organic acids, see Mroz et al. (2006). Although, some bacteria may be resistant against acid environments (De Lange et al., 2010), it is stated that $\mathrm{E}$. coli is not resistant against low pH (Heo et al., 2012).

Several studies have been performed to the effects of organic acids on pig performances (Edmonds et al., 1985; Giesting and Easter, 1985; Tsiloyiannis et al., 2001; Li et al., 2008; Apajalahti et al., 2009; Taube et al., 2009; Chu et al., 2013). Chu et al. (2013) found that bamboo charcoal and bamboo vinegar (which contain organic acids) had a positive influence on growth performance, feed intake, immunoglobulin concentrations (IgG, IgA, and IgM), faecal Salmonella spp. and faecal microflora counts and that this was comparable to that of the use of antimicrobial growth promoters (Chu et al., 2013). Apajalahti et al. (2009) examined formic acid and methionine hydroxyl analogue-free acid on their effect on the ileal microbiota of swine. This study showed that these acids were able to change bacterial growth and metabolism in-vitro. In-vivo only the formic acid showed effects (Apajalahti et al., 2009). Weaned piglets given organic acids (like citric, fumaric, lactic and formic acids) showed improved growth performance and health (Edmonds et al., 1985; Giesting and Easter, 1985; Tsiloyiannis et al., 2001). In a study in-feed organic acids reduced Salmonella and E. coli counts in the stomach of experimentally infected piglets (Taube et al., 2009). Another study which performed a challenge test with organic acids is performed by Li et al. (2008).

\subsection{Objectives}

The objective of the current study was to assess the performance and health promoting properties of fermented corn in pigs by i) reviewing the knowledge in literature on fermentation of pig feed by various strains of Lactobacillus, its generation of dietary organic acids, and its effects on pig performance and health, ii) testing the combined use of a starch degrading enzyme and a strain of lactic acid forming bacteria during corn fermentation on lactic acid production, and iii) the effect of fermented versus unfermented corn on dry matter digestibility by use of an in vitro method.

\subsection{Sponsor}

This research was commissioned and funded by the Dutch Ministry of Economic Affairs within the framework of the public-private partnership 'Kleinschalige Bioraffinage' (PPS AF-12040) with project number BO-21.04-001-001. 


\section{$2 \quad$ Literature review}

\section{$2.1 \quad$ Review}

Fermentation of starchy products by strains of Lactobacillus leads to the generation of organic acids, and both strains of Lactobacillus and organic acids are known for their ability to enhance performance and health of growing pigs. However, the beneficial effects of fermentation on pig economy and wellbeing depend on the type of microbiota used and of the composition of organic acids generated by fermentation. The process of fermentation can be initiated under natural environmental microbial conditions or can be standardised by inoculation with (blends of) specific bacterial strains. The latter may lead to a more predictable generation of different types of organic acids and the chosen bacterial strains for inoculation of the dietary substrate may act as probiotics, being species-specific, i.e specifically originating from the intestine of pigs (Lallès et al. 2007, Allen et al. 2013)

The main product of fermentation is lactic acid and to a lesser extent acetic acid and some ethanol. The ratio between lactic acid and acetic acid should ideally be $>5: 1$ in pigs diet for performance enhancing effects (Scholten 2001, Van der Peet-Schwering et al. 2004)

Naturally fermented chopped corn yields on average 45,3 grams of lactic acid and 19,6 grams of acetic acid per kg dry matter ( $n=1000$ samples, personal communication by G. Abbink (BLGG AgroXpertus). According to Mroz et al. (2006) the minimum inhibitory concentration (MIC) for E. coli is $0.4 \%$ for lactic acid, however, in combination with other organic acids the MIC may be less, as occurs during fermentation of starchy products. At a $12.5-25 \%$ (dry matter) inclusion level of fermented chopped corn in the diet of pigs, the concentration of lactic acid may be around $0.5-1 \%$, a level exceeding the MIC for E. coli.

Inoculation of chopped corn with specific microbial strains may improve standardisation of the fermentation process. Fermentation of corn starch has been initiated before (Vishnu et al. 2002) by inoculation with Lactobacillus amylophilus GV6, a strain with a starch to lactic acid conversion efficiency of more than $80 \%$ when using crude starchy substrates. Lactobacillus amylophilus GV6, is an amylolytic lactic acid producing organism, isolated from cornstarch processing industrial wastes using MRS medium. In addition to Lactobacillus amylophilus GV6, it may be wise to also inoculate with pig specific probiotics to improve pig's health. Micro-organisms which co-evolved with the pig may have specific anti-pathogenic actions and beneficial effects on the pig's immune system due to millions years of cross-talk and interplay between microbe and host.

Several pig specific microbial strains, capable of producing lactic acid, have been isolated, including the Lactobacillus strains MB 3123 (L. johnsonii), MB 3182 (L. salivarius group) and MB 3083 (L. plantarum). Out of 146 pig specific strains, these 4 were found to be very effective for the production of fermented liquid feed based on the capacity to produce lactic acid. No performance studies were conducted (Missottena et al. 2009).

Lactobacillus plantarum 4.1, and Lactobacillus reuteri 357 were selected out of 35 pig specific strains based on their bile salt resistance, $\mathrm{pH}$ tolerance, antimicrobial activity by De Angelis et al. (2006). No performance studies were conducted.

Lactobacillus reuteri and Lactobacillus salivarius were selected out of 94 lactic acid bacterial isolates of porcine origin based on their general probiotic properties (bile and $\mathrm{pH}$ tolerance) of which the former generally had the best intestinal adhesion capacity, whereas the latter appeared to be the best inhibitor of pathogens (Lähteinen et al. 2010). No performance studies were conducted.

Lactobacillus salivarius and Lactobacillus reuteri were selected out of 485 lactic acid bacteria of pig origin, based on probiotic properties. These strains were compatible in the coexistence assay, suggesting that they can be used simultaneously in vivo as multistrain probiotic (Guo et al. 2010). No performance studies were conducted.

Multi-microbe probiotics (comprising Lactobacillus acidophilus, Bacillus subtilis, Saccharomyces cerevisiae and Aspergillus oryzae) were prepared by submerged liquid (LF) and solid substrate 
fermentation (SF) methods and added to a basal pig diet at an inclusion level of $0.3 \%$. Lactobacillus acidophilus was of porcine origin, Bacillus subtilis was isolated from natto (fermented soy bean), Saccharomyces cerevisiae and Aspergillus oryzae were isolated from koji (malted wheat). The results indicated that multi-microbe probiotics prepared by SF method were superior to probiotics prepared by LF in improving growth performance and being beneficial to gut microflora and reducing harmful gut microflora in weaning pigs (Choi et al. 2011).

Pediococcus acidilactici NRRL B-5627, Lactococcus lactis subsp. lactis CECT 539, Lactobacillus casei subsp. casei CECT 4043 and Enterococcus faecium CECT 410 proved to enhance performance in pigs when used separately and supplemented as probiotic to basal pig feed. It is not clear whether these microbial strains are of pig or other origin (Guerra et al. 2007).

Another study ( $\mathrm{Li}$ et al. 2011) reported better pig performance at 5\% inclusion level of fermented potato pulp. Solid state fermentation was induced by anaerobic microbes including Streptococcus thermophiles (CGMCC No. 1.2471), Bacillus subtilis (MA 193) and Saccharomyces cerevisae (CGMCC No. 2.1793). It is not clear whether these microbial strains are of pig or other origin.

\subsection{Conclusions from literature}

Taken together, the multi-microbe probiotics approach of Choi et al. (2011) may result in the best chance to improve pig performance and health by feeding pigs a diet partly consisting of inoculated fermented chopped corn. A corn specific Lactobacillus amylophilus GV6 (Vishnu et al. 2002) may be used in combination with one or more pig specific probiotics like Lactobacillus acidophilus,

Lactobacillus salivarius, Lactobacillus reuteri, Lactobacillus plantarum and Lactobacillus johnsonii depending on the availability of these strains. Commercially available pig probiotics may be used as alternative source of inoculation, if no restrictions to the use apply. An inoculation level of $0.2-0.3 \%$ to the fermentable substrate seems optimal (Yang et al. 2006, Choi et al. 2011). 


\section{Effect of corn fermentation on lactic acid concentration and in vitro dry matter digestibility}

\subsection{Lactic acid in pig diets}

It can be concluded from literature (chapter 2) that dietary supplementation of fermented corn to pigs improved performance and gut health of these pigs. These effects were explained by the presence of lactic acid producing bacteria, which enriched the corn with lactic acid. The mode of action of organic acids, e.g. lactic acid, is a reducing effect on the dietary buffer capacity, an enhancing effect on digestive enzyme activities, e.g. pepsin, a stimulation of pancreatic activity, a reduction of the growth of pathogenic bacteria, a promotion of the growth of favourable bacteria, a reduced velocity of gut emptying, an improved gut integrity, and an increased nutrient digestibility.

The health and growth promoting effects of lactic acid are demonstrated at dietary contents between 50 and 400 mili-equivalents $/ \mathrm{kg}$ diet, which is similar with 4.5 to $36 \mathrm{~g} / \mathrm{kg}$ lactic acid. The lactic acid production during corn fermentation can be effected and stimulated by addition of probiotic strains like Lactobacillus acidophilus, Lactobacillus salivarius, Lactobacillus reuteri, Lactobacillus plantarum and Lactobacillus johnsonii. Based on results from literature, addition of $0.2-0.3 \%$ probiotic to the fermentable product seems to be optimal. In this chapter, the effect of corn fermentation treated with a probiotic strain on lactic acid concentration and subsequently in vitro dry matter digestibility.

\subsection{Material and methods:}

For this study, a batch corn has been fermented. The fermentation procedure was conducted with $1500 \mathrm{~g}$ yellow maize, which was added to 6 I boiling water. This mixture was soaked for 4 hours, while water temperature was maintained at $80-90^{\circ} \mathrm{C}$. Thereafter, fermentation process was stimulated by adding the starch degrading enzyme StarGen (Genencor, Leiden, The Netherlands) and by inoculating the mixture with the lactic acid forming bacteria Bacillus Coagulans LMG6326. The lactic acid forming bacteria were cultivated in our lab, and the remaining pellet fraction after centrifugation was added to the mixture. Fermentation was conducted in a climate room at a constant temperature of $50^{\circ} \mathrm{C}$. In the solution, acidity was maintained at $\mathrm{pH} 5$, by adding sodium hydroxide $(\mathrm{NaOH})$ via an automatic equipment.

The fermentation process lasted for 7 days, where after 3 samples were taken from the batch. These samples were analysed for lactic acid and acetic acid content. Moreover, the in vitro dry matter digestibility of each sample was determined by use of the Boisen method (Boisen and Fernandez, 1997). It was hypothesised that the dry matter digestibility of fermented corn would be increased compared to soaked unfermented corn.

In vitro dry matter digestibility

The Boisen method (Boisen and Fernandez, 1997) was used to determine the in vitro dry matter digestibility of the original and the fermented corn. This method distinguished a short and long procedure. The short procedure simulates the nutrient digestibility of nutrients in the stomach and small intestine of monogastrics, whereas the long procedure includes the simulation of the nutrient digestibility of the large intestine as well. In the current study, the short method was applied in duplicate on each sample. Soaked unfermented corn and soybean meal were included in the study as reference ingredients.

In short, the principle of the method was as follows. To simulate the functioning of the stomach, finely ground ingredients were added to a phosphate buffer solution $(0.1 \mathrm{M}, \mathrm{pH}=6.0)$. $\mathrm{HCL}$ was added to the solution to reduce the acidity to $\mathrm{pH}$ 2.0. The enzyme pepsin was added to stimulate protein degradation. The reaction time for this mixture was 2 hours, whereas temperature was remained 
constant at $39^{\circ} \mathrm{C}$. To simulate the functioning of the small intestine, after 2 hours the mixture was added to a phosphate buffer solution $(0.2 \mathrm{M}, \mathrm{pH}=6.8)$. Pancreatin was added to stimulate fat digestion. The reaction time for this mixture was 4 hours, whereas temperature was remained constant at $39^{\circ} \mathrm{C}$. The undigested residues were then collected in a filtration unit by using dried and pre-weighed glass filter crucibles. All material was then transferred with water to the crucible. After consecutive washings ( 3 min each time) with $2 \times 10 \mathrm{ml}$ of ethanol (96\%) and acetone

$(99.5 \%)$, respectively, the undigested residues were dried at $130^{\circ} \mathrm{C}$ until constant weight for obtaining values of dry matter digestibility).

\subsection{Results and discussion}

Lactic acid and acetic acid contents

The determined contents of lactic acid and acetic acid ( $\mathrm{g} / \mathrm{kg} \mathrm{DM}$ ) of the samples are provided in Table 1.

\section{Table 1}

Determined contents of starch, lactic acid and acetic acid ( $\mathrm{g} / \mathrm{kg} \mathrm{DM}$ ) of the samples

\begin{tabular}{lcccc}
\hline Product & DM & $\begin{array}{c}\text { Starch } \\
(\mathrm{g} / \mathrm{kg} \text { DM })\end{array}$ & $\begin{array}{c}\text { Acetic acid } \\
(\mathrm{g} / \mathrm{kg} \text { DM })\end{array}$ & $\begin{array}{c}\text { Lactic acid } \\
(\mathrm{g} / \mathrm{kg} \text { D M })\end{array}$ \\
\hline Soaked unfermented corn & 964.9 & 691.9 & 0.11 & $<1.0$ \\
Fermented corn sample 1 & 897.4 & 29.2 & 1.85 & 124 \\
Fermented corn sample 2 & 897.6 & 29.5 & 1.94 & 124 \\
Fermented corn sample 3 & 893.0 & 30.2 & 1.92 & 121 \\
\hline
\end{tabular}

Starch content of unfermented corn amounted $692 \mathrm{~g} / \mathrm{kg} \mathrm{DM}$, whereas starch content of the fermented corn samples was reduced to on average $29.6 \mathrm{~g} / \mathrm{kg}$ DM. In the soaked unfermented corn, contents of acetic and lactic acid were very low. In the three fermented corn samples, a small increase in acetic acid content (on average $1.9 \mathrm{~g} / \mathrm{kg} \mathrm{DM}$ ) was observed. Lactic acid content of the fermented corn samples was significantly increased (on average $123 \mathrm{~g} / \mathrm{kg} \mathrm{DM}$ ) as compared to the soaked unfermented corn. According to Abbink (personal communication), naturally fermented corn yields on average 45,3 grams of lactic acid and 19,6 grams of acetic acid per kg dry matter. Because of inoculation with the lactic acid strain, the ratio between lactic acid and acetic acid significantly changed in the fermented corn in the current study, as compared with naturally fermented corn.

According to the review, dietary lactic acid content should amount 4.5 to $36 \mathrm{~g} / \mathrm{kg}$ DM to have a stimulating effect on gut health and pig performance. To realize such contents in a complete pig diet, the inclusion level of the current fermented corn have to vary between 3.6 to $29 \%$ of DM.

In vitro dry matter digestibility

In Table 2, the results of the in vitro dry matter digestibility are presented.

\section{Table 2}

In vitro dry matter digestibility (\%) and standard deviation of the tested samples

\begin{tabular}{lcc}
\hline Product & $\begin{array}{c}\text { Dry matter } \\
\text { digestibility }(\%)\end{array}$ & $\begin{array}{c}\text { Standard } \\
\text { deviation }\end{array}$ \\
\hline Soaked unfermented corn & 88 & 0.9 \\
Fermented corn sample 1 & 94 & 0.9 \\
Fermented corn sample 2 & 94 & 0.1 \\
Fermented corn sample 3 & 93 & 0.2 \\
Soybean meal (reference) & 82 & 0.8 \\
\hline
\end{tabular}


On average, the dry matter digestibility of the three fermented corn samples amounted $94 \%$, which was $6 \%$ higher as compared to the soaked unfermented corn. The dry matter digestibility of soybean meal amounted 82\%. Boisen and Fernandez (1997) determined a total tract organic matter digestibility of corn and soybean meal of $91.4 \%$ and $90.2 \%$, respectively. Differences between their and our findings might be explained by the fact that the current study present the dry matter digestibility, which because of the generally low inorganic matter digestibility is usually lower than the organic matter digestibility. Moreover, the step that simulates the large intestine was not included in the current study. This last step simulates in particular the degradation of the NSP (fibre) fraction.

The increase in dry matter digestibility of the fermented corn was in line with our hypothesis. Because of addition of the starch degrading enzyme, starch particles would be solubilized in the mixture, where after it could be served as an energy source for the lactic acid producing bacteria, thereby converting the starch to lactic acid. Lactic acid is soluble in water (O'Neil, 2001) and ethanol (Lewis, 2001), and therefore passed the filter. The difference in dry matter digestibility between fermented and unfermented corn might be explained by a higher part of insolubilized starch granules in the unfermented corn after 6 hours of incubation.

The used in vitro method is not able to quantify the expected positive effects of fermented corn on gut health. For quantifying this, another in vitro method, e.g. with intestinal pork epithelial cells, or an in vivo study would be recommended.

\subsection{Conclusions}

- The applied fermentation process resulted in a significant increase in the lactic acid content of the fermented corn, without seriously increasing the acetic acid.

- The in vitro digestibility of fermented corn increased by $6 \%$ as compared to soaked unfermented corn.

- According to the current review, dietary lactic acid content should amount 4.5 to $36 \mathrm{~g} / \mathrm{kg} \mathrm{DM}$ to have a stimulating effect on gut health and pig performance. To realize such contents in a complete pig diet, the inclusion level of the current fermented corn have to vary between 3.6 to $29 \%$ of DM. 


\section{References}

Allen HK, UY Levine, T Looft, M Bandrick, TA Casey. 2013. Treatment, promotion, commotion: antibiotic alternatives in food-producing animals. Trends in Microbiology, 21, 114-119.

Amezcua MDR, R Friendship, C Dewey, JS Weese, C de Lange, G Reid. 2007. Effects on growth performance, feed efficiency, and health of weanling pigs fed fermented liquid whey inoculated with lactic acid bacteria that inhibit Escherichia coli in vitro. J Swine Health Prod. 15, 320-329.

Apajalahti J, M Rademacher, JK Htoo, M Redshaw, A Kettunen. 2009. Divergent modulation of swine ileal microbiota by formic acid and methionine hydroxyl analogue-free acid. Animal, vol. 3, pp. 817-825.

Barton MD, WS Hart. 2001. Public health risks: Antibiotic resistance: review. Asian-Australian J ournal of Animal Science, vol. 14, pp. 414-422.

Boisen, S., and J. A. Fernandez. 1997. Prediction of the total tract digestibility of energy in feedstuffs and pig diets by in vitro analyses. Anim. Feed Sci. Technol. 68(3-4):277-286.

Burel C. 2012. Alternatives to antimicrobial growth promoters (AGPs) in animal feed. pp. 432-448. In: Fink-Gremmels, J. (eds.). Animal Feed Contamination; effects on livestock and food safety. Woodhead Publishing Limited (Woodhead Publishing Series in Food Science, Technology and Nutrition, part 4).

Canibe N, BB Jensen. 2003. Fermented and nonfermented liquid feed to growing pigs: Effect on aspects of gastrointestinal ecology and growth performance. J ANIM SCI, 81:2019-2031.

Canibe N, BB Jensen. 2012. Fermented liquid feed - Microbial and nutritional aspects and impact on enteric diseases in pigs. Anim Feed Sci Technol, doi:10.1016/j.anifeedsci.2011.12.021.

Chander Y., SC Gupta, SM Goyal, K Kumar. 2007. Perspective antibiotics: Has the magic gone? Journal of the Science of Food and Agriculture, vol. 87, pp. 739-742.

Cho JH, PY Zhao, IH Kim. 2011. Probiotics as a dietary additive for pigs: A review. Journal of Animal and Veterinary Advances, vol. 10, pp. 2127-2134.

Choi JY, PL Shinde, SL Ingale, JS Kim, YW Kim, KH Kim, IK Kwon, BJ Chae. 2011. Evaluation of multimicrobe probiotics prepared by submerged liquid or solid substrate fermentation and antibiotics in weaning pigs. Livestock Science 138, 144-151.

Chu GM, CK Jung, HY Kim, JH Ha, JH Kim, MS Jung, SJ Lee, Y Song, RIH Ibrahim, JH Cho, SS Lee, YM Song. 2013. Effects of bamboo charcoal and bamboo vinegar as antibiotic alternatives on growth performance, immune responses and fecal microflora population in fattening pigs. Animal Science Journal, vol. 84, pp. 113-120.

De Angelis M, S Siragusa, M Berloco, L Caputo, L Settanni, G Alfonsi, M Amerio, A Grandi, A Ragni, M Gobbetti. 2006. Selection of potential probiotic lactobacilli from pig feces to be used as additives in pelleted feeding. Research in Microbiology 157, 792-801.

Decuypere JA, NA Dierick. 2003. The combined use of triacylglycerols containing medium-chain fatty acids and exogenous lipolytic enzymes as an alternative to in-feed antibiotics in piglets: concept, possibilities and limitations. An overview. Nutrition Research Reviews, vol. 16, pp. 193-209. 
De Lange CFM, J Pluske, J Gong, CM Nyachoti. 2010. Strategic use of feed ingredients and feed additives to stimulate gut health and development in young pigs. Livestock Science, vol. 134, pp. 124-134.

Dibner JJ, P Buttin. 2002. Use of organic acids as a model to study the impact of gut microflora on nutrition and metabolism. Journal of Applied Poultry Research, vol. 11, pp. 453-463.

Diebold G, U Eidelsburger. 2006. Acidification of diets as an alternative to antibiotic growth promoters. pp. 311-327. In: Barug, D., De Jong, J., Kies, A.K., Verstegen, M.W.A. (eds.) Antimicrobial Growth Promoters: Where do we go from here?. Wageningen Academic Publishers, The Netherlands.

Edmonds MS, OA Izquierdo, DH Baker. 1985. Feed additive studies with newly weaned pigs: efficacy of supplemental copper, antibiotics and organic acids. Journal of Animal Science, vol. 60, pp. 462469.

Giesting DW, RA Easter. 1985. Response of starter pigs to supplementation of corn-soybean meal diets with organic acids. Journal of Animal Science, vol. 60, pp. 1288-1294.

Guerra NP, PF Bernárdez, J Méndez, P Cachaldora, LP Castroa. 2007. Production of four potentially probiotic lactic acid bacteria and their evaluation as feed additives for weaned piglets. Animal Feed Science and Technology 134, 89-107.

Guo XH, JM Kim, HM Nam, SY Park, JM Kim. 2010. Screening lactic acid bacteria from swine origins for multistrain probiotics based on in vitro functional properties. Anaerobe 16, 321-326.

Heo JM, FO Opapeju, JR Pluske, JC Kim, DJ Hampson, CM Nyachoti. 2012. Gastrointestinal health and function in weaned pigs: a review of feeding strategies to control post-weaning diarrhoea without using in-feed antimicrobial compounds. Journal of Animal Physiology and Animal Nutrition, vol. 97, pp. 207-237.

Jacela JY, JM DeRouchey, MD Tokach, RD Goodband, JL Nelssen, P David, G Renter, SS Dritz. 2010. Feed additives for swine: Fact sheets - prebiotics and probiotics, and phytogenics. J Swine Health Prod. 2010;18(3):132-136.

Knarreborg A, N Miquel, BB Jensen. 2002. Establishment and application of an in vitro methodology to study the effects of organic acids on coliform and lactic acid bacteria in the proximal part of the gastrointestinal tract of piglets. Animal Feed Science and Technology, vol. 99, pp. 131-140.

Lähteinen T, E Malinen, JMK Koort, U Mertaniemi-Hannus, T Hankimo, N Karikoski, S Pakkanen, H Laine, H Sillanpää, H Söderholm, A Palva. 2010. Probiotic properties of Lactobacillus isolates originating from porcine intestine and feces. Anaerobe 16, 293-300.

Lallès JP, P Bosi, H Smidt, CR Stokes. Nutritional management of gut health in pigs around weaning. 2007. Proceedings of the Nutrition Society 66, 260-268.

Lewis, R.J. Sr.; Hawley's Condensed Chemical Dictionary 14th Edition. John Wiley \& Sons, Inc. New York, NY 2001., p. 649

Li PF, LF Xue, RF Zhang, XS Piao, ZK Zeng, JS Zhan. 2011. Effects of fermented potato pulp on performance, nutrient digestibility, carcass traits and plasma parameters of growing-finishing pigs. Asian-Aust J Anim Sci 24 (10) 1456-1463.

Li Z, G Yi, J Yin, P Sun, D Li, C Knight. 2008. Effects of organic acids on growth performance, gastrointestinal $\mathrm{pH}$, intestinal microbial populations and immune responses of weaned pigs. The Asian-Australian Journal of Animal Science, vol. 21, pp. 252-261. 
Martinez FAC, EM Balciunas, JM Salgado, JMD Gonzalez, A Converti, RP de Souza Oliveira. 2013. Lactic acid properties, applications and production: A review. Trends in Food Science \& Technology 30 : 70-83.

Missottena JAM, J Gorisb, J Michielsa, E Van Coillieb, L Hermanb, S De Smeta, NA Diericka, M Heyndrickx. 2009. Screening of isolated lactic acid bacteria as potential beneficial strains for fermented liquid pig feed production. Animal Feed Science and Technology,150,122-138.

Mroz Z, SJ Koopmans, A Bannink, K Partanen, W Krasucki, M Øverland, S Radcliffe. 2006. Carboxylic acids as bioregulators and gut growth promoters in nonruminants. pp. 81-133. In: Mosenthin $R$, Zentek J, Żebrowska T. (eds.). Biology of Nutrition in Growing Animals. Elsevier.

Namkung H, M Li, J Gong, H Yu, M Cottrill, CFM de Lange. 2004. Impact of feeding blends of organic acids and herbal extracts on growth performance, gut microbiota and digestive function in newly weaned pigs. Can. J. Anim. Sci. 84:697-704.

O'Neil, M.J. (ed.). The Merck Index - An Encyclopedia of Chemicals, Drugs, and Biologicals. 13th Edition, Whitehouse Station, NJ: Merck and Co., Inc., 2001., p. 955

Papatsiros VG, PD Tassis, ED Tzika, DS Papaioannou, E Petridou, C Alexopoulos, SC Kyriakis. 2011. Effect of benzoic acid and combination of benzoic acid with a probiotic containing Bacillus Cereus var. toyoi in weaned pig nutrition. Polish Journal of Veterinary Sciences 14, 117-125.

Papatsiros VG, G Christodoulopoulos, LC Filippopoulos. 2012. The use of organic acids in monogastric animals (swine and rabbits). Journal of Cell and Animal Biology 6(10),154-159. Available online at http://www.academicjournals.org/JCAB DOI: 10.5897/JCAB11.081.

Partanen KH, Z Mroz. Organic acids for performance enhancement in pig diets. 1999. Nutrition Research Reviews, 12, 117-145.

Partanen K. 2001. Organic acids - their efficacy and modes of action in pigs. pp. 201-217. In: Piva, A., Bach Knudsen, K.E., Lindberg, J.E. (eds.). Gut Environment of Pigs. Nottingham University Press, Nottingham United Kingdom.

Sanders ME. Probiotics: Definition, Sources, Selection, and Uses. Clinical Infectious Diseases. 2008. 46:S58-61. DOI: 10.1086/523341.

Scholten RHJ. 2001. Fermentation of liquid diets for pigs. Ph.D. Thesis, Wageningen University, The Netherlands.

Smolders MAHH, MM van Krimpen, RHJ Scholten, DJPH van de Loo. 2000. The influence of lactic acid on performance and health of weaned piglets Praktijkonderzoek Varkenshouderij Proefverslag nummer P 1.246, ISSN 0922 - 8586.

Taube VA, ME Neu, Y Hassan, J Verspohl, M Beyerbach, J Kamphues. 2009. Effects of dietary additives (potassium diformate/organic acids) as well as influences of grinding intensity (coarse/fine) of diets for weaned piglets experimentally infected with Salmonella Derby or Escherichia coli. Journal of Animal Physiology and Animal Nutrition, vol. 93, pp. 350-358.

Tsiloyiannis VK, SC Kyriakis, J Vlemmas, K Sarris. 2001. The effect of organic acids on the control of porcine post-weaning diarrhoea. Research in Veterinary Science, vol. 70, pp. 287-293.

Van der Peet-Schwering CMC, MAHH Smolders, GP Binnendijk, EMAM Bruininx. 2004. Fermented cereals in liquid weaner diets. Praktijkrapport Varkens 36, Animal Sciences Group Wageningen. 
Verstegen MWA, BA Williams. 2002. Alternatives to the use of antibiotics as growth promoters for monogastric animals. Animal Biotechnology, vol. 13, pp. 113-127.

Vishnu C, G Seenayya, G Reddy. 2002. Direct fermentation of various pure and crude starchy substrates to $\mathrm{L}(+)$ lactic acid using Lactobacillus amylophilus GV6. World Journal of Microbiology and Biotechnology 18, 429-433.

Yang SY, KS Ji, YH Baik, WS Kwak, TA McCaskey. 2006. Lactic acid fermentation of food waste for swine feed. Bioresource Technology 97, 1858-1864. 



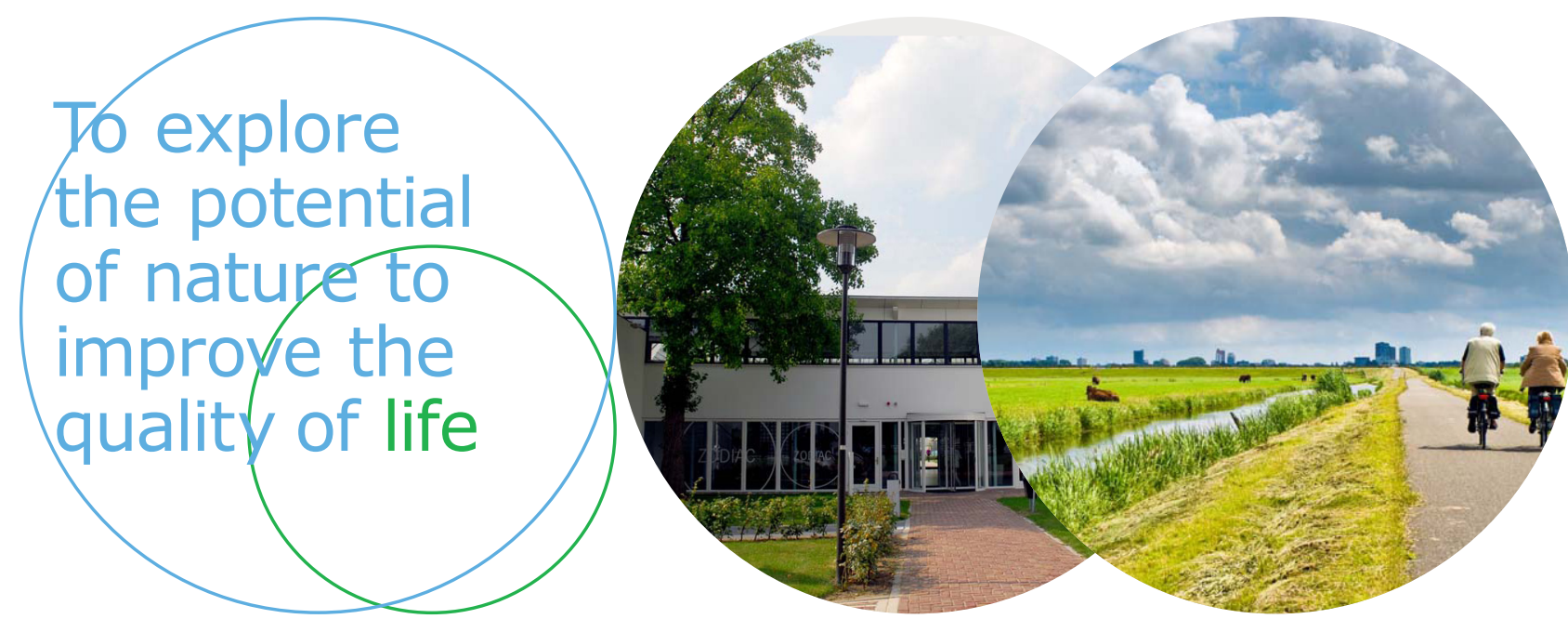

Wageningen UR Livestock Research P.O. Box 65

8200 AB Lelystad

The Netherlands

$\mathrm{T}+31(0) 320238238$

E info.livestockresearch@wur.nl

www.wageningenUR.nl/livestockresearch

http://dx.doi.org/10.18174/384209
Together with our clients, we integrate scientific know-how and practical experience to develop livestock concepts for the 21st century. With our expertise on innovative livestock systems, nutrition, welfare, genetics and environmental impact of livestock farming and our state-of-the art research facilities, such as Dairy Campus and Swine Innovation Centre Sterksel, we support our customers to find solutions for current and future challenges.

The mission of Wageningen UR (University \& Research centre) is 'To explore the potential of nature to improve the quality of life'. Within Wageningen UR, nine specialised research institutes of the DLO Foundation have joined forces with Wageningen University to help answer the most important questions in the domain of healthy food and living environment. With approximately 30 locations, 6,000 members of staff and 10,000 students, Wageningen UR is one of the leading organisations in its domain worldwide. The integral approach to problems and the cooperation between the various disciplines are at the heart of the unique Wageningen Approach. 